\title{
Nifuratel Compared with Metronidazole in the Treatment of Trichomonal Vaginitis
}

\author{
B. A. EVANS, ${ }^{*}$ M.B., B.S. ; R. D. CATTERALL, † F.R.C.P.ED.
}

\begin{abstract}
Cummary: Nifuratel (Magmilor) was compared with $\checkmark$ metronidazole (Flagyl) in the treatment of trichomonal vaginitis by a randomized double-blind trial. Only 18 out of 47 patients $(38 \%)$ treated with nifuratel were found to be cured, whereas 42 out of 49 patients $(85 \%)$ treated with metronidazole were cured. Severe reactions, necessitating withdrawal of treatment, occurred in three patients treated with nifuratel. There were no serious side-effects with metronidazole. The results of this trial indicate that nifuratel is not a satisfactory substitute for metronidazole in the treatment of trichomoniasis.
\end{abstract}

\section{Introduction}

Since its introduction in France 10 years ago metronidazole (Flagyl) has become the standard treatment for trichomonal vaginitis (Durel et al., 1959, 1960; Rodin et al., 1960). It combines ease of administration with a high cure rate and a minimum of unwanted effects. Nifuratel (Magmilor) is a nitrofuran derivative introduced in Italy for the treatment of all forms of vaginal infection (Arnold and Delnon, 1965; Carrera and Dexeus, 1966). It is now available in this country and has been widely used in general practice (Fowler and Hussain, 1968; Orr Struthers, 1969). In the present investigation the two products are compared in the treatment of trichomonal vaginitis.

\section{Patients and Methods}

The trial was carried out on women attending a clinic for sexually transmitted diseases. Most of the patients were aged 18 to $30(86 \%)$ and were single $(79 \%)$. Symptoms suggestive of vaginal inflammation were present in $77 \%$. Nifuratel was administered concurrently by mouth and vaginal pessary as Magmilor tablets $200 \mathrm{mg}$. three times a day for seven days together with one $250-\mathrm{mg}$. pessary nightly for 10 nights. Metronidazole was given by mouth only as Flagyl $200 \mathrm{mg}$. three times a day for seven days.

A series of 115 consecutive patients found to be infected with Trichomonas vaginalis were allotted to one of the two forms of treatment according to a previously prepared random sequence, unknown to the prescriber and unknown to the patient. The use of pessaries in addition to tablets in one schedule, however, made it possible to discover in retrospect which treatment the patient had received.

In most cases the diagnosis was made by dark-ground microscopical examination of a saline suspension of secretion from the posterior vaginal fornix. Some cases were diagnosed only by culture, the Feinberg-Whittington medium being used, and a few were discovered from cervical smears, carried out only at the first examination. The follow-up procedure aimed at obtaining a minimum of two further sets of genital tests to exclude the coexistence of other genital infections, particularly gonorrhoea, and up to a total of five follow-up tests to establish the eradication of $T$. vaginalis. Those patients who continued to attend regularly were kept under observation for a period of 12 weeks from the start of treat-

\footnotetext{
* Senior Registrar, Department of Venereology, the Middlesex Hospital,
} London W.1.

† Director, James Pringle House, the Middlesex Hospital, London W.1. ment. Gram-stained smears of material from the vaginal wall and Sabouraud's medium were used routinely for the detection of Candida albicans, and Gram-stained slides of samples of secretions from the cervix and urethra and chocolate agar medium were used to diagnose gonorrhoea.

\section{Results}

Fifty-six patients were treated with nifuratel and 59 with metronidazole. In the nifuratel group, nine $(16 \%)$ failed to return for further examination and were therefore excluded from the trial. Of the remaining $47,18(38 \%)$ were shown to have been cured on the evidence of at least one set of posttreatment tests. Thirteen were found to be still infected at the first post-treatment examination and 11 at the second examination. The other two were detected on culture of the vaginal secretions at the third and fourth examinations (Table I).

\begin{tabular}{|c|c|c|c|c|c|c|c|c|c|}
\hline \multirow{3}{*}{$\begin{array}{l}\text { Treatment } \\
\text { Group }\end{array}$} & \multicolumn{9}{|c|}{ Positive Examinations After Treatmen: } \\
\hline & \multicolumn{2}{|c|}{$1 \mathrm{st}$} & \multicolumn{2}{|c|}{ 2nd } & \multicolumn{2}{|c|}{ 3rd } & \multicolumn{2}{|c|}{ 4th } & \multirow{2}{*}{ Total } \\
\hline & Slide & $\overline{\text { Culture }}$ & s. & C. & s. & C. & S. & C. & \\
\hline $\begin{array}{l}\text { Nifuratel } \\
\text { Metronidazole }\end{array}$ & $\begin{array}{r}10 \\
2\end{array}$ & $\begin{array}{l}3 \\
1\end{array}$ & $\begin{array}{r}10 \\
3\end{array}$ & 1 & - & 1 & 二 & $\begin{array}{l}1 \\
1\end{array}$ & $\begin{array}{r}26 \\
7\end{array}$ \\
\hline
\end{tabular}

In the group treated with metronidazole, $10(17 \%)$ failed to return for further examination and were removed from the trial. Of the 49 patients who were followed up, $42(85 \%)$ were found to be cured after one set of post-treatment tests. Three were still harbouring $T$. vaginalis at the first posttreatment examination and three at the second examination. The vaginal culture was positive in one other patient at the fourth examination (Table I).

Three patients receiving nifuratel had to discontinue treatment because of adverse effects. Two developed irritant rashes; in one case the face was affected after four days of treatment and in the other a generalized urticaria was produced within 12 hours of starting treatment. The third patient complained of drowsiness and loss of memory from the start of treatment. All three patients were subsequently treated with metronidazole. There were no side-effects and they were all cured of their trichomonal vaginitis. One patient taking metronidazole complained of diarrhoea and vomiting, but continued to take the tablets.

In the nifuratel group, $C$. albicans was grown on culture in five patients before treatment and in two after treatment, while in the metronidazole group, the organism was isolated in three patients before treatment and in six after treatment. None of the findings after treatment in either group corresponded to the pre-treatment findings.

Gonorrhoea, confirmed bacteriologically, was diagnosed before treatment in 10 out of 56 patients treated with nifuratel $(17.5 \%)$ and in 16 out of the 59 treated with metronidazole $(27 \%)$. All these patients were treated with intramuscular penicillin. During the 12-week period of observation gonorrhoea was diagnosed in only one patient treated with metronidazole, seven weeks after the treatment and following the resumption of intercourse. Three of the patients 
treated with nifuratel subsequently developed gonorrhoeafive, seven, and 11 weeks after treatment. One of these developed acute salpingitis and all of them had resumed sexual intercourse.

\section{Discussion}

The results of this trial indicate that nifuratel in the recommended dosage is of limited value in the treatment of trichomonal vaginitis when compared with metronidazole, the standard treatment. A cure rate of only $38 \%$ was obtained with nifuratel compared with a cure rate of $85 \%$ with metronidazole (Table II). Furthermore, adverse reactions severe enough to necessitate withdrawal of treatment occurred in three patients treated with nifuratel; there were two cases of hypersensitivity and one patient experienced a narcotic effect. Metronidazole did not show this disadvantage.

Apparent failure of medication may well result from reinfection in all forms of sexually transmitted diseases. In

TABle II.-Negative Examinations on Cured Patients

\begin{tabular}{|c|c|c|c|c|c|c|c|c|c|}
\hline \multirow{2}{*}{\multicolumn{5}{|c|}{ Treatment Group }} & \multicolumn{5}{|c|}{ Number of Negative Examinations } \\
\hline & & & & & \multirow{2}{*}{$\begin{array}{c}1 \\
11 \\
15\end{array}$} & \multirow{2}{*}{$-\frac{2}{4}$} & \multirow{2}{*}{$\begin{array}{l}3 \\
1 \\
8\end{array}$} & \multirow{2}{*}{$\begin{array}{l}4 \\
2 \\
2\end{array}$} & \multirow{2}{*}{$\begin{array}{c}\text { Tota } \\
18 \\
42\end{array}$} \\
\hline $\begin{array}{l}\text { Nifuratel } \\
\text { Metronidazole }\end{array}$ & $\begin{array}{l}\cdots \\
\cdots\end{array}$ & $\begin{array}{l}\cdots \\
\cdots\end{array}$ & $\begin{array}{l}\cdots \\
\cdots\end{array}$ & $\begin{array}{l}\ldots \\
\ldots\end{array}$ & & & & & \\
\hline
\end{tabular}

the patients studied, however, trichomonas reappeared only twice after two negative examinations, during a 12-week follow-up period, when nifuratel was used and only once after metronidazole. This finding is consistent with a low reinfection rate. There was insufficient evidence to support the finding of Churcher and Evans (1969) that nifuratel may mask gonorrhoea and so delay the diagnosis. Neisseria gonorrhoeae was found in only three patients after treatment with nifuratel; these were all more than five weeks later, and there was every reason to believe that they had been reinfected. Among the 49 patients treated with metronidazole, $N$. gonorrhoeae was isolated in only one case during the 12-week observation period.

\section{REFERENCES}

Arnold, M., and Delnon, J. (1965). Therapeutische Umschau und Medizinische Bibliographie, 22, 490.

Carrera, J. M., and Dexeus, S. (1966). Revista Española de Obstetrica y Ginecologia, 25, 308.

Churcher, G. M., and Evans, A. J. (1969). British fournal of Venereal Diseases, 45, 149.

Durel, P., Roiron, V., Siboulet, A., and Borel, L. J. (1959). Comptes Rendus de la Société Francaise de Gynécologie, 29, 36.

Durel, P., Roiron, V., Siboulet, A., and Borel, L. J. (1960). British fournal of Venereal Diseases, $36,21$.

Fowler, W., and Hussain, M. (1968). British fournal of Venereal Diseases, 44, 331 .

Diseases, 44, 331.
Rodin, P., King, A. J., Nicol, C. S., and Barrow, J. (1960). British fournal of Venereal Diseases, 36, 147.

Struthers, J. O. (1969). British fournal of Clinical Practice, 23, 417.

\section{Preliminary Communications}

\section{Interaction of Diazepam with the Muscle-Relaxant Drugs}

\section{British Medical fournal, 1970, 2, 336-338}

Sumr mmary: Diazepam has been found to increase the duration of the neuromuscular block produced by gallamine and to reduce that produced by succinylcholine. Preliminary studies suggest that the action is at the presynaptic site.

The benzo-diazepine derivatives are among the most commonly prescribed drugs-Librium (chlordiazeproxide), Valium (diazepam), Mogadon (nitrazepam). Diazepam is an effective tranquillizer when used orally in small doses (0.1$0.25 \mathrm{mg}$. $/ \mathrm{kg}$. body weight) and a hypnotic when administered in the same dose intramuscularly or intravenously (Strovner and Endresen, 1965, 1966; Brown 1968; Hellewell, 1968). Intravenous diazepam is now widely used in psychiatry, anaesthesia, dentistry, and general medical practice. Apart from its propensity to cause pain along the injected vein in a few patients, and a tendency to produce venous thrombosis, diazepam, in the doses recommended, appears to have few deleterious effects. The cardiovascular system is unaffected by the agent (Reitan et al., 1970), and only a very temporary effect on ventilation has been recorded (Hellewell, 1968).

Pharmacological studies with diazepam (Zbinden and Randall, 1967) revealed pronounced skeletal musrle relaxation in both animals and man. This is associated with noticeable anticonvulsant properties (Watson, 1968). In analysing the mechanism involved in producing this relaxant effect, Ngai et al. (1966) showed that polysynaptic spinal reflexes are delayed while monosynaptic reflexes are not. Parkes (1968) failed to find any effect on neuromuscular transmission. It was there- fore concluded that diazepam acted by depressing interneuronal transmission in the spinal cord.

During the course of our experiments on neuromuscular conduction we have observed that diazepam profoundly affects the action of the muscle-relaxant drugs. We wish to draw the attention of anaesthetists to the hazard that may result from the effect of diazepam on curare-like drugs.

\section{METHOD}

Neuromuscular transmission was studied by recording the force of contraction of the adductor pollicis longus muscle when the ulnar nerve was stimulated. The nerve was stimulated with supramaximal stimuli every five seconds, delivered from either a Wellcome peripheral nerve stimulator or a Palmer Physiological stimulator to needle electrodes inserted over the course of the ulnar nerve at wrist and elbow. A Statham UC3 strain gauge was used to measure the force of thumb adduction (Tyrrell, 1969). Patients undergoing surgery during which diazepam, alone or in combination with a muscle relaxant, was to be used were included in this study. All patients were induced with thiopentone, and anaesthesia was maintained with nitrous oxide and oxygen ( $30 \%$ oxygen) with $0.5-1 \%$ added halothane. The effect of diazepam 0.15 to 0.2 $\mathrm{mg} . / \mathrm{kg}$. alone and with gallamine and succinylcholine was studied.

When the patients were stabilized the control twitch response of the adductor pollicis longus was recorded. Gallamine 40-60 mg. was given intravenously. The extent of the neuromuscular block produced by this dose of gallamine was determined by the maximum depression of twitch height and the duration of the $25-75 \%$ twitch height recovery time. This compared satisfactorily with the results obtained in similar circumstances in a previous study (Feldman and Tyrrell, to be published). The action of the gallamine was 